\title{
Differentiation Strategies of Internet Retailing (Unique, Value and Return): A Focused Web Evaluation into Airline Service Provider
}

\author{
Mohd Zulkeflee Bin Abd Razak \\ School of Labuan International Business and Finance \\ Universiti Malaysia Sabah, Labuan International Campus \\ Jalan Sungai Pagar, 87000 F.T Labuan, Malaysia \\ Tel: 60-87-460-512 E-mail: zulrazak@ums.edu.my \\ Azleen Ilias (Corresponding author) \\ School of Labuan International Business and Finance \\ Universiti Malaysia Sabah, Labuan International Campus \\ Jalan Sungai Pagar, 87000 F.T Labuan, Malaysia \\ Tel: 60-87-460-517E-mail: neelza80@yahoo.co.uk \\ Rahida Abdul Rahman \\ School of Labuan International Business and Finance \\ Universiti Malaysia Sabah,Labuan International Campus \\ Jalan Sungai Pagar, 87000 F.T Labuan, Malaysia
}

\begin{abstract}
Differentiation is defined as the process of adding a set of meaningful and valued differences to distinguish the company's offering from competitors' offerings (Kotler, 2003, p. 315). Karl Cluck of Razorfish, recommends that "online marketers must enhance the user's online experience in order to entice potential customers to buy" ("New York E-Commerce," 2000, p. 1). A company can differentiate itself by creating a unique customer experience such as superior customer service and in turn, brand the experience. Through experience branding, 'firms can greatly improve their ability to retain customers, target key customers segments and enhance network profitability’ (Vincent, 2000, p.25). The internet interactivity allows companies to respond more quickly to customer requests. Moreover, the ever-increasing speed of the Internet allows companies to communicate more quickly with current and potential customers, which is essential to retaining current customers and attracting new ones. The main purpose of the case study is to review and evaluate AirAsia's website by applying Seven Unique Differentiation Strategies to Online Businesses (site environment/ atmospherics, making the intangible tangible, building trust, efficiency and timely order processing, pricing, CRM and enhancing the experience). In this study, qualitative data from AirAsia website was analyzed and discussed through proposed concise list of Seven Unique Differentiation Strategies to Online Businesses by Strauss and Frost, 2006. The study is expected to improve the differentiation of organization's image and service information availability and accessibility on the Web in future. Finally, Researches agree to look into further the changes that should be made to enhance the Air Asia website evaluations and that changes are pertaining to virtual tours, appealing the 3-D images, immediate customer response and better "On Time Acknowledgement" for AirAsia CRM.
\end{abstract}

Keywords: Differentiation strategy, Online business, Web evaluation, Airline service provider

\section{Introduction}

Recently, the internet has become one of the most rapidly growing retail formats, with online sales growth rates outpacing those in traditional retail settings (Burns, 2005; Levy and Weitz, 2001). Growth in the number of internet shoppers and the percent of internet sales are expected to continue (Maloy, 2003; Siddiqui et al., 2003). Markets believe that the development of internet retailing is showing an increment to the sales of each e-tailer. 
Researchers believe that the existence of website as the key element of connection between internet retaling and customers has become the main idea of why this study is done. Existing evidence from research points to the importance of website attributes to consumers' online shopping behaviour, with certain attributes playing a major role in creating demand for online purchasing and increasing store transactions and sales (Lohse and Spiller, 1998; Lorek, 2003; Magee, 2003; Maloy, 2003; Retail Merchandiser, 2003; Rowley and Okelberry, 2000; Swaminathan et al., 1999; Zellweger, 1997).

AirAsia is an airline company that now flies to over 60 destinations in Malaysia, Thailand, Indonesia, Singapore, China, Philippines, Brunei, Cambodia, Laos, Vietnam and Myanmar. They have formed two (2) successful joint ventures in Thailand through Thai AirAsia, and Indonesia through Indonesia AirAsia. They have also expanded their fleet from the original two to twenty eight, and revolutionized air travel in these countries by offering incredibly low fares through their innovative sales channels. With the tagline 'Now everyone can fly', AirAsia's philosophy of low fares is aimed to make flying affordable for everyone. AirAsia also aims at making travel easy, convenient and fun for its guests. Therefore, part of the AirAsia key strategies are concerning into guest convenience and it refers to the idea of providing ticketless services, easy payment channels, internet booking and improving customer service. These key strategies deal with the internet transaction (through the AirAsia Website) and will require customers and future customers interest in browsing through the whole processes from the beginning to the end. Transaction will only be made once the customer had less complicatedness and had no bad experience.

In this study, the researches focus into the ability of AirAsia Website in meeting up with the global trends of customers' acceptance. The purposes of the case study are:

1). To review and evaluate AirAsia's website based on site environment/ atmospherics

2). To review and evaluate AirAsia's website based on making the intangible tangible

3). To review and evaluate AirAsia's website based on building trust

4). To review and evaluate AirAsia's website based on efficiency and timely order processing

5). To review and evaluate AirAsia's website based on pricing

6). To review and evaluate AirAsia's website based on CRM

7). To review and evaluate AirAsia's website based on enhancing the experience

The remainder of this paper is organized as follows. A review of related literature on differentiation strategies and seven unique differentiation strategies to Online Businesses. Next, the methodology employed in this study and website analysis method involved are described. Finally, the content website analysis results and discussion of the study are drawn.

\section{Literature Review}

\subsection{Differentiation Strategies}

Kotler defines differentiation as "the process of adding a set of meaningful and valued differences to distinguish the company's offering from competitors' offerings' (Kotler, 2003, p. 315). A firm can differentiate its offering along five dimensions: product, services, personnel, channel, and image (Kotler, 2003). These dimensions are discussed as follows:

\subsubsection{Product Differentiation}

Traditional offline differentiation emphasized the product dimension; the other areas have been used when little real difference exists between competing products. Companies still differentiate by product features online. However, the Internet's greatest contribution is in product line differentiation, that is, the literally limitless assortment of products that companies are able to offer and the ability to capitalize on this huge assortment as a platform to customize product offerings for individual customers. Internet marketing may have a major effect on product packaging. At present, marketers design most product packaging to appeal to consumers, be eye catching, compete with other products on store shelves, and sell the products. As more commerce is conducted online rather in retail stores, consumers might require products with more utilitarian packaging. Products purchased online will be shipped from the distributor directly to the consumer and, thus, never appear on retailers' shelves. As a result, these products will not require the expensive, colourful packaging that is necessary for store display; nor will they require multiple layers of functional and display packaging.

\subsubsection{Service Differentiation}

Services can effectively differentiate an online business in several ways. Customer service is enhanced by the ability to receive customer feedback through e-mail 24 hours a day, even if telephone operators and customer service personnel are not available and this will show the ability to respond more rapidly (in real time) to customer concerns. Another aspect of service differentiation is the distribution of products ordered online. Some companies are specializing in the 
home delivery of products ordered online, thus differentiating their services from most traditional offline services. Other online services, such as online banking and securities trading, are becoming increasingly popular, differentiated both by the features they offer and the service consumption experiences. These services currently supplement traditional offline services, but as the world becomes more interconnected via the Internet, they may one day replace the traditional offline services.

\subsubsection{Personnel Differentiation}

In the past, personalized service and one-to-one relationships between merchants and consumers required costly skilled personnel. Now, the Internets allows companies to 'deliver their products and services through low-cost channels that automate the process and remove the expensive human element' (Wells et all., 200, pg.32). By reducing a company's dependence on personnel to handle business transactions, the Internet leads to lower transaction cost, enabling a cost leadership advantage over offline companies. It "also results in cist reduction for the end user and at the same time acts as a differentiation by providing higher levels of service at lower prices." (Chakravarthy, 2000, p.2). However, as more companies offer products and services online, the cost advantage between online and offline operations will gradually shrink over time.

\subsubsection{Channel Differentiation}

The Internet doubles as a location-free and time-free distribution and communication channel. The Internet expands companies' reach from local to global, 24 hours a day, and with a limitless assortment of products. Customers may order a wider variety of products, at any time, day or night, for shipment to any location in the world, in contrast to the limited product assortment and limited business hours of traditional brick-and-mortar companies. Online channel differentiation occurs on multiple levels. First, companies that provide product or service information on the Web have an advantage over companies with no web presence by exploiting the Internet as a communication channel. Second, companies that conduct commercial transactions online capitalize on the advantage of the Internet's properties as a transaction and distribution channel. At a higher level is the differentiation of competitors' Internet-related service offerings. For example, in the banking industry, "one my provide a 'virtual pass book' facility, while another may transact on behalf of the client, and a third may actually provide interactive portfolio management services to key account holders' (Chakravarthy, 2000, p.2). Finally, highly specialized personal services-"Do it yourself," Websites allows users to conduct activities such as transfer phone service and pay bills online.

\subsubsection{Image Differentiation}

Karl Cluck of Razorfish, recommends that "online marketers must enhance the user's online experience in order to entice potential customers to buy" ("New York E-Commerce," 2000, p.1). A company can differentiate itself by creating a unique customer experience such as superior customer service and, in turn, brand the experience. Through experience branding, "firms can greatly improve their ability to retain customers, target key customers, target key customer segments and enhance network profitability" (Vincent, 2000, p.25).

The Internet's interactivity allows companies to respond more quickly to customer requests. Moreover, the ever-increasing speed of the Internet allows companies to communicate more quickly with current and potential customers, which is essential to retaining current customers and attracting new ones. Consider the pure-play home furnishing business, iHome, which is " addressing customer requests to receive decorating help on a budget...iHome's ability to get download time under 30 seconds" is the key to iHome's growth rate" (Slott, 2000, p.38). All of these benefits help to differentiate the image and the customer experience of online firms. For example, AOL and Venus Swimwear have online chat features to help customers with questions about their purchases.

\subsection{Seven Unique Differentiation Strategies to Online Businesses}

According to Strauss and Frost, 2006 these strategies are of particular importance on the Internet because the marketing strategy often revolves around the company's image and product information available on the Web. In addition to the preceding strategies are unique to online businesses consist of site environment/ atmospherics, making the intangible tangible, building trust, efficiency and timely order processing, pricing, CRM and enhancing the experience.

\subsubsection{Site Environment/ Atmospherics}

Atmospherics refers to the in-store ambiance created by brick-and-mortar retailers. Similarly, Websites can be differentiated by providing visitors with a positive environment to visit, search, purchase, and so forth. Visitors want a site that easily downloads, portrays accurate information, clearly shows the products and services offered, and is easily navigated. If customers view the homepage and like what they see, they are more likely to view additional pages and ultimately become a paying customer.

\subsubsection{Making the Intangible Tangible}

A purely online product or service can only be seen through an image or description. Whether a company uses virtual tours, 3-D images, product image enlargements trial downloads, or customer reviews, the goal is to make offerings seem more tangible by showing them in a realistic and customer-friendly manner. 


\subsubsection{Building Trust}

Trust is a key issue on the Internet, especially when customers are expected to pay online or their information is tracked for personalized service or supply chain management. For this reason, rust building should be an integral part of a Website's marketing strategy. In some instances trust may be appeared as a by-product of strong brand recognition; however, a company site with low or no brand recognition must project a secure environment. Detmer (2002) makes the following suggestion to e-marketers:

Take the time to clearly define your company's privacy policy, and make sure it is strictly enforced.... Maintaining the balance between privacy and personalization will increase the comfort level your customers feel for your business.

In addition to stating the privacy policy, e-commerce firms can reassure customers by using a safe and encrypted payment process for transactions. Trust is also important if customers should encounter problems on the Website, require personal assistance, or need to exchange or return a purchase. Visitors may be more likely to buy from a site if they know a live person can be contacted.

\subsubsection{Efficiency and timely Processing}

One of the strongest motivators for customers who make Web-based purchases is the ease of ordering. Organizations must market their alliances and delivery timeliness as an important benefit. Furthermore, if the online company follows through on its promises, it is more likely to build customer loyalty and receive referrals from satisfied customers. Customer satisfaction or dissatisfaction can spread very quickly on the Internet with just few keystrokes.

\subsubsection{Pricing}

Pricing as a method of differentiation has come under scrutiny, especially for Web marketers. When products were first offered on the Web, companies tended to offer price discounts as an incentive. Today, prices are relatively comparable on the Web, although some companies, such as Buy.com, offer lower prices. The majority of firms choose to differentiate themselves using methods other than pricing because pricing is easy to imitate and non price differentiation is more enduring for all but the price leaders.

\subsubsection{Customer Relationship Management (CRM)}

As more firms shift away from price differentiation and as barriers to entry decrease on the Internet, customer relationship management (CRM) becomes more predominant as a means of differentiation. Netflix, for example, forges long-term relationships with consumers who want the convenience of receiving movies on DVD by mail. Customers who subscribe to one of Netflix's monthly plans can set up personal lists of the movies they want to rent. Depending on the type of subscription they choose, customers can rent three or more DVD movies at one time with no return deadlines or late return penalties. After viewing a movie, customers slip it into the prepaid return envelope to mail it back to Netflix, a few days later, they receive the next DVD on their list. Thus, Netflixs builds customers relationships one at a time through customer-driven personalization including a personal greeting on the Web site.

\subsubsection{Enhancing the Experience}

Another type of differentiation strategies is discussed in a E-Marketing Opportunity Model (Feeny, 2001). This model helps companies to differentiate using one of three e-marketing opportunities: enhancing the selling process, enhancing the customer buying process, and enhancing the customer usage experience. In this model, firms use perceived product differentiation and frequency of purchase to choose the best approach.

\section{Methodology}

The study will evaluate each of the strategy and researchers will point out the analysis through their observations and experiences. This will lead into in-depth discussion on how the customer perceived the value of the website and chances of involving into bad experience of transaction or vice versa. In summary, differentiation is what a company does to the product, services and processes. As stated by Strauss and Frost, 2006, differentiation strategies have evolved with the commercialization of the Internet. The keys to differentiating online businesses are the creation of a distinctive and superior customer experience and the development of one-to-one relationships with consumers. The real value added by the Internet is the enhanced ability to differentiate according to customer relationship and provide a unique experience for each customer. Therefore, making a different will turn the whole perception and defection to an acceptance.

These differentiation strategies are:

1). Site environment/ atmospherics

2). Making the intangible tangible

3). Building trust

4). Efficiency and timely order processing

5). Pricing 


\section{6). CRM}

\section{7). Enhancing the experience}

\section{Analysis and Discussion}

\subsection{AirAsia's Site Environment / Atmospherics}

Based on AirAsia's Website (Figure 1) researchers found that the site environment is fascinating and create fresh ambiance to the customers in welcoming them to browse further. Here, we found that the colour (red colour) plays as a major element in creating the appearance to be $100 \%$ appeal compared to the other website of airline service providers. The interactive buttons help the viewers to easily connected and conduct the session from one page to another. Piece of information is easily downloaded and portrays accurate information as listed like flight booking, pricing, package offered and other valid and useful information. The Website is clearly shows the products and services offered as it refers to the ability of the company in granting the promises made. Basic information are all listed as these always required for the first time viewers or users in not making them lost throughout the browsing. Researches also found that the element of promotions is always becoming the main factor to be advertised in the website as it creates sense of "knowing more". This leads into the potentiality of creating sales and up to making profit to the AirAsia. Analysis made always found that the navigation is considered as "user friendly" and this is a key of becoming preferable airline service provider by the customers and potential customers.

\subsection{Making the Intangible Tangible}

As referring to Figure 1, it shows that AirAsia Website is providing lots of elements of "Making the Intangible Tangible" such as On Time Performance, On Time Guarantee, GoInsure, attractive pictures of places to visit, sitemap and others. Researches concern that by offering those elements have waken up the mood of realistic, becoming lively and customer-friendly manner. This will lead into attractions of becoming satisfied and loyal customer.

\subsection{Building Trust}

First and foremost, researches believe that through the recognitions awarded to the AirAsia, it appears as the major trust element in making the customer and potential customer become confident in dealing with the whole transaction with AirAsia. This can be seen through the listed awards shown in AirAsia Website (http://www.airasia.com/amazing/en/pageWithHeader.php?menu=one\&content=one_awards). Those awards act as the evidence of making their promises into reality. Next is about the assurance of using a safe and encrypted payment process for transactions. It is not a denial that AirAsia Website is one of the best secured sites of doing internet transactions. This security aspect is proven by looking into the whole processes of buying and doing payment for the services offered. As evidence, this can be referred to Figure 2 (A) and 2 (B). Through AirAsia Website, it convinces the customer to become more relax and less hassle pertaining any queries about the transactions due to the availability of listed contact number and addresses as it connects the customer and potential customer to the AirAsia personal assistance which is a live person that can be contacted. It proves that AirAsia is always maintaining in building customer's trust. This supporting argument is shown in AirAsia Website (http://www.airasia.com/site/en/page.jsp;jsessionid=4589D22505F7F46D81B4AD505A02B0AB? name=Contact+Us\&i $\mathrm{d}=1 \mathrm{~b} 7 \mathrm{a} 37 \mathrm{dc}-\mathrm{ac} 1 \mathrm{e} 00 \mathrm{ae}-511 \mathrm{e} 0 \mathrm{a} 00-34 \mathrm{df6}$ a10\&nav=6-1).

\subsection{Efficient and Timely Order Processing.}

As others, AirAsia provides the customers and potential customers an instant payment system where it focuses on delivering immediate purchasing services. Meaning that, the customer has the opportunity in doing the purchasing process at anytime, anywhere upon customer preferences. Experiencing the purchasing ticket process through AirAsia Website has given the best opportunity to the researches as it offers alternatives in mode of payment compared to the other airline service providers. Here, AirAsia has given the best solutions in doing payment by giving options either paying by credit card or debit card. This option helps most of the customers or potential customers due to the cases that not everyone is having a credit card. Figure 3 shows the alternative in mode of payment system provided by AirAsia and Figure 2 (A) as well as Figure 2 (B) is supporting the statement of getting the opportunity of doing the purchasing process at anytime and anywhere. Figure 2 (B) is also a virtual evidence for customer reference if customer or potential customer encounter problems in the future. It will be emailed to customer email address based on customer choice.

\subsection{Pricing}

AirAsia's fares are significantly lower than those of other airline service providers. This is a fact that accepted by the market particularly competitors. AirAsia's Website fares are much cheaper compared to the frontline counter price and this is also one of the differentiation strategy that implemented by Airasia in order to attract more customers to purchase online through the website. Researches found that, the differentiation pricing strategy applied by AirAsia is valuing the company to be demanded more than their expectation. This is the key strategy that still cannot be beaten up by any other competitors and has guaranteed higher return to AirAsia since the day they started their operation. Researches 
believe that the promotion pricing strategy has enhanced AirAsia reputation in making the promises become reality; "Now Everyone Can Fly". This tagline has become the benchmarking to the company in giving better fares at every promotional booking offer. Figure 1 supports the above statements and it is recommended to visit AirAsia Website (http://www.airasia.com/site/my/en/home.jsp ) for a better proven.

\subsection{Customer Relationship Management (CRM)}

Researchers believe that AirAsia always determine the customers as their first priority in every consideration. This can be seen into the first page of the AirAsia Website which has stated the member log in button. Customer or potential customers can always be connected to the AirAsia programmes such as promotional booking offers, news updates, phone circulars, flight changes info and others. Becoming AirAsia members will bring customers to an advance information that will ensure members are always one's step ahead from others. These are the benefits that can be gathered from becoming members of the company. All particular data of customers are secured and will be guaranteed for personalization from AirAsia. All statements are supported by Figure 1 and an experience of becoming members at http://www.airasia.com/site/my/en/home.jsp.

\subsection{Enhancing the Experience}

From the beginning of operation until now, AirAsia has incurred a huge development in every prospect of services provided. The development has created outstanding improvement especially in the AirAsia Website application. Researches accept as true that the development leads into satisfaction of selling process, customer buying process and customer usage experience. Experience can only be gained once we are in the process. Therefore, due to less hassle given throughout the whole processes, researchers believe that AirAsia can be considered successful in delighting the customers. To ensure the statement is correct and supported with evidence, please have the practicality in browsing the AirAsia Website at http://www.airasia.com/.

\section{Conclusion and Recommendation}

In this study, researchers found that the ability of AirAsia to gain attractions from the customers and potential customers to viewing and browsing their website is by applying differentiation strategies. This study has shown that AirAsia is successfully proven that their interactive website is mutually meeting the standard of customer satisfaction and AirAsia can proudly stands as one of the most reliable and potential airline service provider that can provide better services through their website applications. Researchers believe that in the next few years, AirAsia Website will become the best ever retail website that fulfill the customers and potential customers demands and wants.

As for recommendations, researches agree to look into further the changes that should be made to enhance the AirAsia Website evaluations and that changes are pertaining to virtual tours of places to be visited, chances of appealing the 3-D images for more attractions, immediate customer response and better "On Time Acknowledgement" (particularly for flight delay and cancellation) for AirAsia CRM.

\section{References}

Chakravarthy, Srinivas. (2000). E-Strategy: Different Strokes. Businessline. October 4, pp.1-2.

Detmer, T. (2002). Seeking the Complete Customer Experience: The Web as a Marketing Tool. Customer Inter@ction Solutions. Vol.20. No.11. p.45.

Feeny, D. (2001). Marketing Business Sense of the E-Opportunity. MIT Sloan Management Review (Winter).p. 45.

Kotler., P. (2003). Marketing Management. $11^{\text {th }}$ Ed. Upper Saddle River, NJ: Prentice Hall.

Lohse, G.L., Spiller, P. (1998). Electronic shopping: the effect of customer interfaces on traffic and sales. Communications of the ACM, Vol. 41. No. 7. pp 81-87.

Lorek, L.A. (2003). Buyers catch on to online shopping. San Antonio Express-News. [Available: http://web.lexix-nexix.com/universe/document]

Magee, M. (2003). Boom or bust for e-shopping. The Sunday Tribune. [Available: http://web.lexix-nexix.com/universe/document]

Maloy, T.K. (2003). Net is here to stay for retailers. [Available: http://web.lexix-nexix.com/universe/document]

New York E-Commerce Association Presents Experts on Online Branding; Industry Leading Internet Companies Discuss the Challenges of Creating Differentiation on the Web. (2000). Business Wire. March 22. p. 1.

Retail Merchandiser. (2003). Online spending jumps 18 per cent. [Available: http://web.lexix-nexix.com/universe/document]

Rowley, K.L. and Okelberry, A. (2000). Shopping.com: analysis of a trend. Journal of Family and Consumer Sciences, Vol.92. No.1, pp 9-10. 
Seock., Y.K. and Norton., M.J.T. (2007). Capturing college students on the web: analysis of clothing web site attributes. Journal of Fashion Marketing and Management. Vol. 11. No. 4. ISSN: 1361-2026.

Slott., M. (2000). Store Strategies at Center Stage. Home Textiles Today. Vol. 21. No. 43. pp. 35-38.

Strauss. J, El-Ansary., A. and Frost., R. (2006). E-Marketing. $4^{\text {th }}$ Ed. Pearson Prentice Hall.

Swaminathan, V., Lepkowska-White, E. and Rao, B. (1999). Browser or buyers in cyberspace? An investigation of factors influencing electronic exchange. Journal of Computer-mediated Communication. Vol. 5. No. 1. [Available: www.ascusc.org/jcmc/vol5/issue1/swaminathan.html]

Tillotson., J. (2002). Web site evaluation: a survey of undergraduates. Online Information Review. Vol. 26. No. 6. ISSN: $1468-4527$.

Vincent, L. (2000). The Brand That Binds, Bank Marketing, vol. 32, no. 11, pp. 24-29.

Wells., N., Jeff., W. and Richard. C.R. (2000). Finance with a personalized Touch. Association for Computing Machinery. Communication of the ACM. Vol. 43. No. 8.pp.31-34.

Zellweger, P. (1997). Web-based sales: defining the cognitive buyer. Electronic Markets. Vol. 7. No.3. pp 10-16.

Availability: http://www.airasia.com/.

Availability: http://www.airasia.com/amazing/en/pageWithHeader.php?menu=one\&content=one_awards Availability:

http://www.airasia.com/site/en/page.jsp;jsessionid=4589D22505F7F46D81B4AD505A02B0AB?name=Contact+Us\&id $=1 \mathrm{~b} 7 \mathrm{a} 37 \mathrm{dc}-\mathrm{ac} 1 \mathrm{e} 00 \mathrm{ae}-511 \mathrm{e} 0 \mathrm{a} 00-34 \mathrm{df} 6 \mathrm{a} 10 \& \mathrm{nav}=6-1$

Availability: http://www.airasia.com/site/my/en/home.jsp

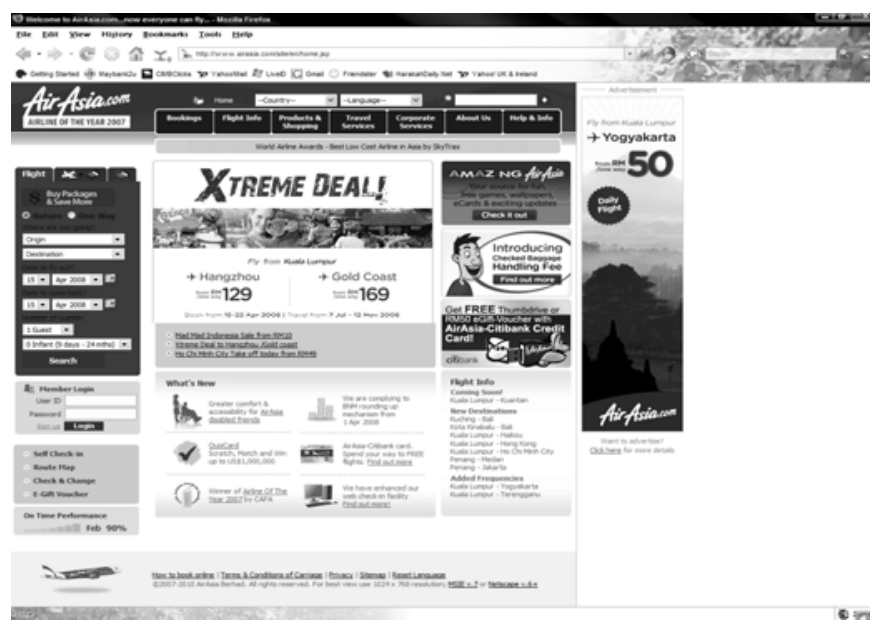

Figure 1. Airasia Main Page 


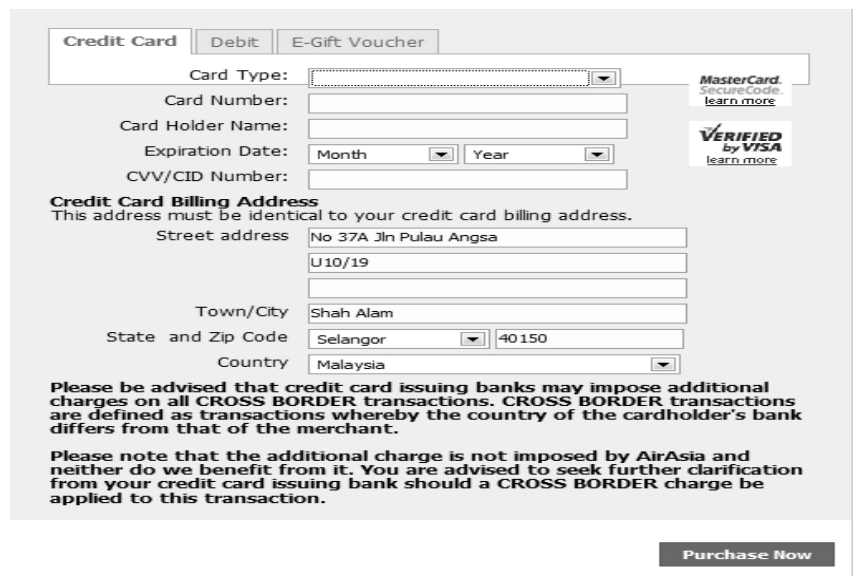

Figure 2 (A). Part of Online Purchasing Process

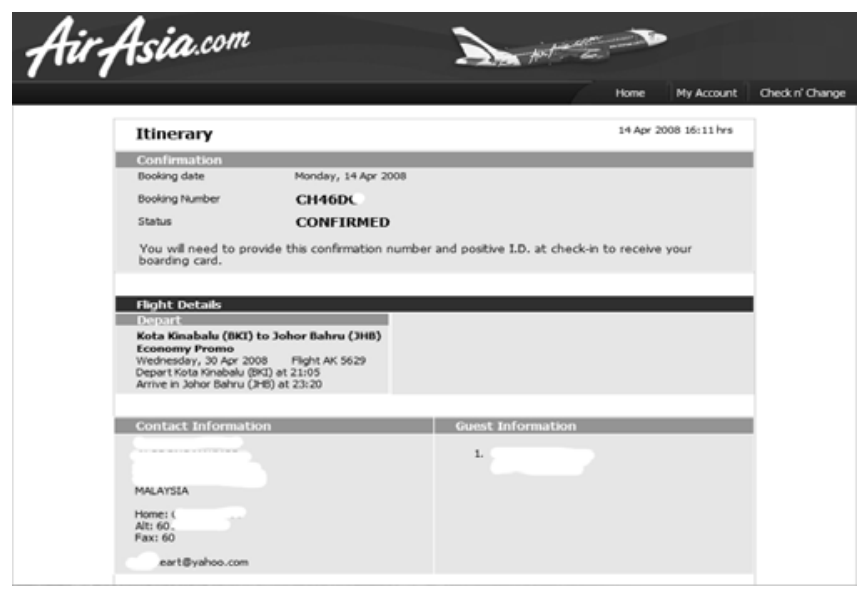

Figure 2 (B). Completed Form of Confirmation

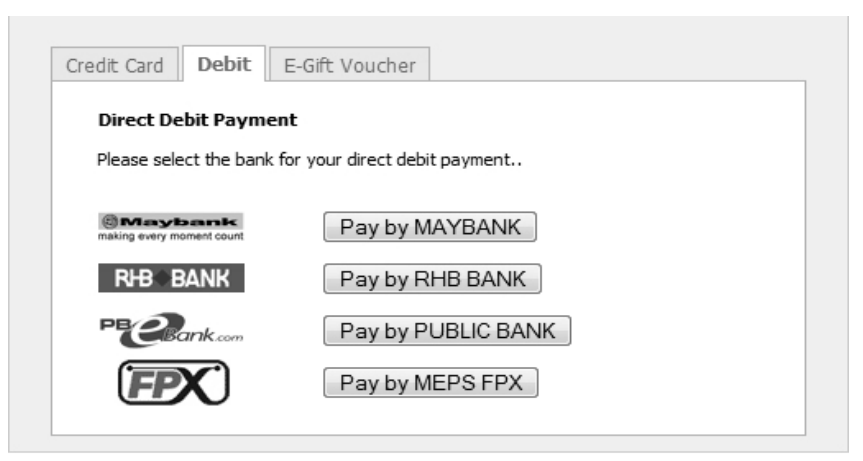

$\frac{\text { Terms \& Conditions of Carriage I Privacy }}{(92007-2010 \text { AirAsia Berhad }}$

Figure 3. Alternative in Mode of Payment System 